\title{
Can COPD Patients Who Hyperinflate During Daily Life Activities Be Identified by Laboratory Tests?
}

\author{
A. Lahaije $H$. van Helvoort R. Dekhuijzen Y. Heijdra \\ Radboud University Nijmegen Medical Centre, Department of Pulmonary Diseases, Nijmegen, The Netherlands
}

For editorial comment see p. 177

\section{Key Words}

Dynamic hyperinflation - Metronome-paced tachypnea .

Cardiopulmonary exercise testing

\begin{abstract}
Background: Identification of patients with chronic obstructive pulmonary disease (COPD) who develop dynamic hyperinflation $(\mathrm{DH})$ during activities in daily life (ADL) is important, because of the association between $\mathrm{DH}$ and dyspnea and exercise limitation. Objective: We aimed to answer the question whether measurements of $\mathrm{DH}$ during metronomepaced tachypnea (MPT) or cardiopulmonary exercise testing (CPET) can be used to identify patients who develop DH during ADL. Methods: DH was measured by tracking changes in inspiratory capacity during CPET, MPT and ADL. BlandAltman plots were used to evaluate agreement in $\mathrm{DH}$ between methods. With a receiver operating characteristic (ROC) analysis, the overall accuracy of MPT and CPET to identify patients who hyperinflate during ADL was assessed. $\boldsymbol{R e}$ sults: There are broad limits of agreement in DH between methods. ROC curve analyses showed good overall accuracy of both CPET and MPT to identify patients who hyperinflate during $\mathrm{ADL}$. For $\mathrm{CPET}$, area under the curve $(\mathrm{AUC})=0.956$ (95\% Cl 0.903-1.009). For MPT, AUC $=0.840$ (95\% Cl 0.699$0.981)$. Sensitivity and specificity to identify patients who hyperinflate during ADL with CPET were 96 and 83\%, respectively, and with MPT, they were 89 and $77 \%$, respectively.
\end{abstract}

Conclusion: Both CPET and MPT can serve as screening tools to identify patients who are susceptible to developing $\mathrm{DH}$ during ADL. In practice, MPT is the most simple and inexpensive surrogate. However, the sensitivity of MPT is not optimal. When DH does not occur during CPET, it is unlikely to occur during ADL.

Copyright @ 2013 S. Karger AG, Basel

\section{Introduction}

Dynamic hyperinflation (DH) is an important phenomenon in chronic obstructive pulmonary disease (COPD). The increase in end-expiratory lung volume (EELV), which defines $\mathrm{DH}$, is associated with dyspnea and exercise limitation $[1,2]$ which are both major complaints in COPD patients. Commonly, $\mathrm{DH}$ is assessed through symptom-limited or constant workload cardiopulmonary exercise testing (CPET). For study purposes, DH has also been assessed with metronome-paced tachypnea (MPT), which has been shown to be a simple, reliable alternative to CPET when it comes to comparing $\mathrm{DH}$ between groups $[3,4]$. So far, it remains unknown whether the $\mathrm{DH}$ measured in laboratory settings, i.e. CPET and MPT, reflects the DH that occurs during activities in daily life (ADL) that cause dyspnea $[5,6]$. From a clinical point of view, it is interesting to know whether a patient with COPD is predisposed to develop $\mathrm{DH}$ during $\mathrm{ADL}$.

\section{KARGER}

E-Mail karger@karger.com

www.karger.com/res
C 2013 S. Karger AG, Basel

0025-7931/13/0863-0237\$38.00/0
Anke Lahaije, MSc

Radboud University Nijmegen Medical Centre

Department of Pulmonary Diseases, 454

Geert Grooteplein Zuid 8, NL-6500 HB Nijmegen (The Netherlands)

E-Mail alahaije@ hotmail.nl 
$\mathrm{DH}$ leads to an increase in operating lung volumes, which eventually stiffens the lungs and thus requires an increased effort to inhale. On the other hand, the diaphragm can generate less inspiratory pressure due to $\mathrm{DH}$ [7]. This might explain why, in COPD, DH is related to a decline of physical activity [8]. In clinical practice, however, it is not practical and often not possible to test if a patient develops $\mathrm{DH}$ in response to $\mathrm{ADL}$.

In a previous study, we compared MPT-induced DH with CPET-induced DH [4]. It is likely that the amount of DH during ADL will be less than during CPET, as minute ventilation and breathing frequency are lower during submaximal activities [1], as seen in most ADL. The main objective of this study was to answer the question whether or not the measurement of DH during MPT or CPET can identify patients who develop DH during ADL.

\section{Methods}

Between November 2009 and March 2012, patients with mild to very severe COPD were recruited from the outpatient clinic of the Radboud University Nijmegen Medical Centre and the University Centre for Chronic Diseases in the Netherlands. Patients participated in a study on ADL.

The inclusion criteria were: a diagnosis of COPD and clinical stability (defined as no exacerbations for at least 6 weeks). Exclusion criteria were: other respiratory diseases, long-term oxygen therapy, recent participation in a pulmonary rehabilitation program and disorders which could possibly interfere with exercise testing (severe or unstable heart disease and neuromuscular or musculoskeletal disorders). The study was approved by the local medical research ethics committee and all patients gave their written informed consent.

Design

Measurements of DH were taken during CPET, MPT and ADL. During a visit to the hospital, pulmonary function was measured and CPET was performed according to the guidelines of the American Thoracic Society and the European Respiratory Society [9-11]. In addition, an MPT test [3] was performed. Measurements during ADL were scheduled at the patients' homes within 9 days of CPET.

\section{Measurement of $\mathrm{DH}$}

The amount of DH during CPET, ADL and MPT was derived from measurements of inspiratory capacity (IC). Assuming constant total lung capacity (TLC) $[12,13]$, a decrease in IC reflects an increase in EELV and thus DH (EELV = TLC - IC). All patients were instructed on the performance of the IC maneuvers prior to each test. After four consistent end-expiratory levels, monitored by the real-time display of tidal breathing, the patient was encouraged to inspire to TLC and then to return to normal breathing. At the start of each test, baseline IC was measured by taking the mean of three acceptable maneuvers while the patient was at rest $\left(\mathrm{IC}_{\text {rest }}\right)$ [10]. Any deviation in end-expiratory level during the last breath preceding IC was manually adjusted during analysis of the test, considering the three preceding end-expiratory levels. IC measurements taken at peak CPET, immediately after MPT and at the end of ADL were used to assess DH. DH was thus calculated as the difference between these IC measurements and $\mathrm{IC}_{\text {rest }}$ and expressed as the relative change in IC compared to $\mathrm{IC}_{\text {rest }}$.

\section{Cardiopulmonary Exercise Testing}

All subjects performed a symptom-limited incremental CPET [9] using an electrically braked cycle ergometer (Masterlab, Jaeger $^{\circledR}$, Wurzburg, Germany). Patients breathed through a face mask connected to a metabolic system (Oxycon Pro, Jaeger, CareFusion $\mathrm{GmbH}$, Hoechberg, Germany). Breath-by-breath measurements were used to analyze expired gases. Reference equations for the calculation of predicted maximal oxygen uptake $\left(\mathrm{VO}_{2 \text { pred }}\right)$ were those produced by Wasserman et al. [14].

\section{Activities in Daily Life}

Patients selected their individual, most dyspnea-causing ADL. This had to be an activity that was performed regularly so as to ensure we were measuring a regularly occurring phenomenon. Measurements during the ADL were performed at the patients' homes using a portable version of the Oxycon breath-by-breath system (Oxycon Mobile, Jaeger, CareFusion $\mathrm{GmbH}$ ) $[6,15]$. This allowed patients to perform their ADL in the usual way. During the ADL, there was no 'peak' value, so the mean values of the last minute of steady-state ADL were used for analyses of oxygen consumption $\left(\mathrm{VO}_{2}\right)$, minute ventilation (VE) and breathing frequency.

\section{Metronome-Paced Tachypnea}

Subjects were seated, breathing through a mouthpiece connected to the spirometer (MasterScreen-PFT, Jaeger). In accordance with earlier studies [3, 4], MPT was performed at twice the resting breathing frequency. Patients were asked to breathe at this pace for $20 \mathrm{~s}$, immediately followed by a maximal inspiratory maneuver $\left(\mathrm{IC}_{\mathrm{MPT}}\right)$. The procedure was repeated after patients had returned to their resting breathing level. $\mathrm{IC}_{\mathrm{MPT}}$ was calculated as the mean from two acceptable maneuvers, within $10 \%$ of each other (conform [10]).

\section{Pulmonary Function Tests}

Pulmonary function tests included spirometry [10], body plethysmography [11] and determination of carbon monoxide transfer factor $\left(\mathrm{DL}_{\mathrm{CO}}\right)$ [16]. Reference equations for the calculation of predicted values were those produced by the European Community for Steel and Coal [17] and normal values for IC were calculated as predicted TLC minus predicted functional residual capacity (FRC). Severity of airflow obstruction was classified according to the Global Initiative for Chronic Obstructive Lung Disease (GOLD) stages [18].

\section{Statistics}

Measurements of DH with CPET, ADL and MPT $\left(\triangle \mathrm{IC}_{\mathrm{CPET}}\right.$, $\triangle \mathrm{IC}_{\mathrm{ADL}}$ and $\triangle \mathrm{IC}_{\mathrm{MPT}}$, respectively) were compared to a repeatedmeasures ANOVA. Post hoc analyses, with a Bonferroni correction for multiple comparisons, were used for pairwise comparisons of the test results.

A cut-off value of a $10 \%$ decrease in IC was used as a definition of ADL-induced DH and to discriminate between hyperinflators and nonhyperinflators. This cut-off was based on the repeatability 
coefficient of measurements of IC [4]. A relative change in IC $(\triangle \mathrm{IC})$ was chosen over an absolute change, because absolute $\Delta \mathrm{IC}$ is related to the IC value at rest, whereas relative $\Delta \mathrm{IC}$ shows a more homoscedastic distribution $[4,5,19,20]$.

A receiver operating characteristic (ROC) analysis assessed the overall accuracy of MPT and CPET to identify the patients who hyperinflated during ADL. The optimal cut-off points for MPT and CPET were determined and, subsequently, using their optimal cut-off, the sensitivity and specificity of MPT and CPET to identify hyperinflators and nonhyperinflators were assessed.

Values are expressed as mean \pm SEM, unless stated otherwise. Statistical significance was set at $\mathrm{p}<0.05$.

\section{Results}

\section{Characteristics}

A total of 45 patients participated in this study. Their characteristics are described in table 1 . The ADL they performed are described in table 2 . Based on a decrease in IC during ADL that exceeds $10 \%, 28$ patients $(62 \%, \mathrm{n}=4,11$, 10 and 3 for GOLD stages I, II, III and IV, respectively) were classified as hyperinflators during ADL and $17 \mathrm{pa}-$ tients ( $\mathrm{n}=9$ and 8 for GOLD stages I and II, respectively) as nonhyperinflators.

The requirements of ADL in terms of oxygen uptake and minute ventilation were less than those of CPET. $\mathrm{VO}_{2}$ at end ADL was $75.2 \pm 19.3 \%$ of the peak $\mathrm{VO}_{2}(\mathrm{p}<0.001)$ and VE during ADL was $65.5 \pm 18.0 \%$ of the peak $\mathrm{VE}(\mathrm{p}<$ 0.001). VE was highest during CPET and lowest during MPT $(58.0 \pm 2.7 \mathrm{l} / \mathrm{min}$ vs. $35.8 \pm 1.3$ and $31.6 \pm 1.7$ during ADL and MPT respectively, $\mathrm{p}<0.05)$. Breathing frequency was similar during CPET and MPT $(32.8 \pm 1.1$ and $30.2 \pm 1.1$ respectively, $\mathrm{p}>0.05$ ), but lower during $\mathrm{ADL}$ $(26.6 \pm 1.0, \mathrm{p}<0.05)$. Mean ADL-induced $\triangle \mathrm{IC}$ was $-14.8 \pm$ $2.4 \%$ of resting IC. At peak CPET and after MPT, similar amounts of $\mathrm{DH}$ were measured to during $\mathrm{ADL}(\mathrm{p}>0.05)$ $\left(\triangle \mathrm{IC}_{\mathrm{CPET}}-16.2 \pm 2.2 \%\right.$ and $\left.\triangle \mathrm{IC}_{\mathrm{MPT}}-19.3 \pm 1.9 \%\right)$.

Inspection of the individual responses to the three methods, in terms of $\mathrm{DH}$, showed large differences in some patients, leading to wide limits of agreement between the methods, as illustrated with Bland-Altman plots (fig. 1).

Because the methods did not show good agreement, we investigated whether individuals who hyperinflated during ADL (i.e. when IC decreased more than 10\%) could be identified with CPET or MPT. To evaluate the overall accuracy of CPET and MPT to identify patients showing DH during ADL, we performed ROC curve analyses. Classification of patients as hyperinflators or nonhyperinflators during ADL was taken as the reference standard. The area under the curve (AUC) and optimal
Table 1. Patient characteristics

\begin{tabular}{ll}
\hline Patients $(\mathrm{n}=45)$ & Mean \pm SD \\
\hline Age, years & $64.5 \pm 7.0$ \\
Weight, kg & $76.9 \pm 16.1$ \\
BMI, kg/m & $26.1 \pm 4.7$ \\
\hline
\end{tabular}

\section{Pulmonary function}

GOLD stage, I/II/III/IV

$13 / 19 / 10 / 3$

$\mathrm{FEV}_{1}$, liters (\%pred)

$1.86 \pm 0.73(65.3 \pm 23.7)$

$\mathrm{FEV}_{1} / \mathrm{FVC}$, \%

$45.8 \pm 13.7$

TLC, liters (\%pred)

IC ${ }^{\mathrm{a}}$, liters (\%pred)

$\mathrm{RV}$, liters (\%pred)

RV/TLC, \%

$7.48 \pm 1.49(116.3 \pm 23.4)$

$2.80 \pm 0.69(95.1 \pm 19.6)$

$\mathrm{DL}_{\mathrm{CO}}, \%$ pred

$3.56 \pm 1.08(152.7 \pm 45.2)$

$47.2 \pm 9.2$

$59.1 \pm 24.1$

Peak CPET variables

Workload, W

$105 \pm 43$

$\mathrm{VO}_{2}$, liters/min (\%pred)

$1.50 \pm 0.48(82 \pm 21)$

$\mathrm{VE}$, liters/min

$58.0 \pm 17.6$

$\mathrm{DL}_{\mathrm{CO}}=$ Diffusion capacity of the lung for carbon monoxide; $\mathrm{FEV}_{1}=$ postbronchodilator forced expiratory volume in $1 \mathrm{~s} ; \mathrm{FVC}=$ postbronchodilator forced vital capacity; $\mathrm{RV}=$ residual volume; $\mathrm{VE}=$ minute ventilation at peak workload; $\mathrm{VO}_{2}=$ oxygen consumption at peak workload.

a IC was calculated as the difference between TLC and intrathoracic gas volume.

Table 2. Individually chosen dyspnea-causing ADL

\begin{tabular}{ll}
\hline & $\begin{array}{l}\text { Frequency } \\
\text { male/female }\end{array}$ \\
\hline Vacuum-cleaning & $11 / 6$ \\
Sweeping floors & $5 / 2$ \\
Digging in the garden & $4 / 1$ \\
Window-cleaning & $2 / 2$ \\
Carrying bags & $2 / 1$ \\
Stair-climbing & $2 / 1$ \\
Changing beds & $0 / 1$ \\
Dish-washing & $0 / 1$ \\
Hanging laundry & $0 / 1$ \\
Cleaning cupboards & $1 / 0$ \\
Walking the dog & $1 / 0$ \\
Emptying the dishwasher & $0 / 1$ \\
\hline
\end{tabular}

cut-offs for CPET and MPT-induced DH are shown in table 3, together with the sensitivity and specificity of the cut-offs. ROC curves are depicted in figure 2.

With CPET, 4 out of 45 patients were incorrectly classified; 3 nonhyperinflators during $\mathrm{ADL}\left(\triangle \mathrm{IC}_{\mathrm{ADL}}<10 \%\right.$ 


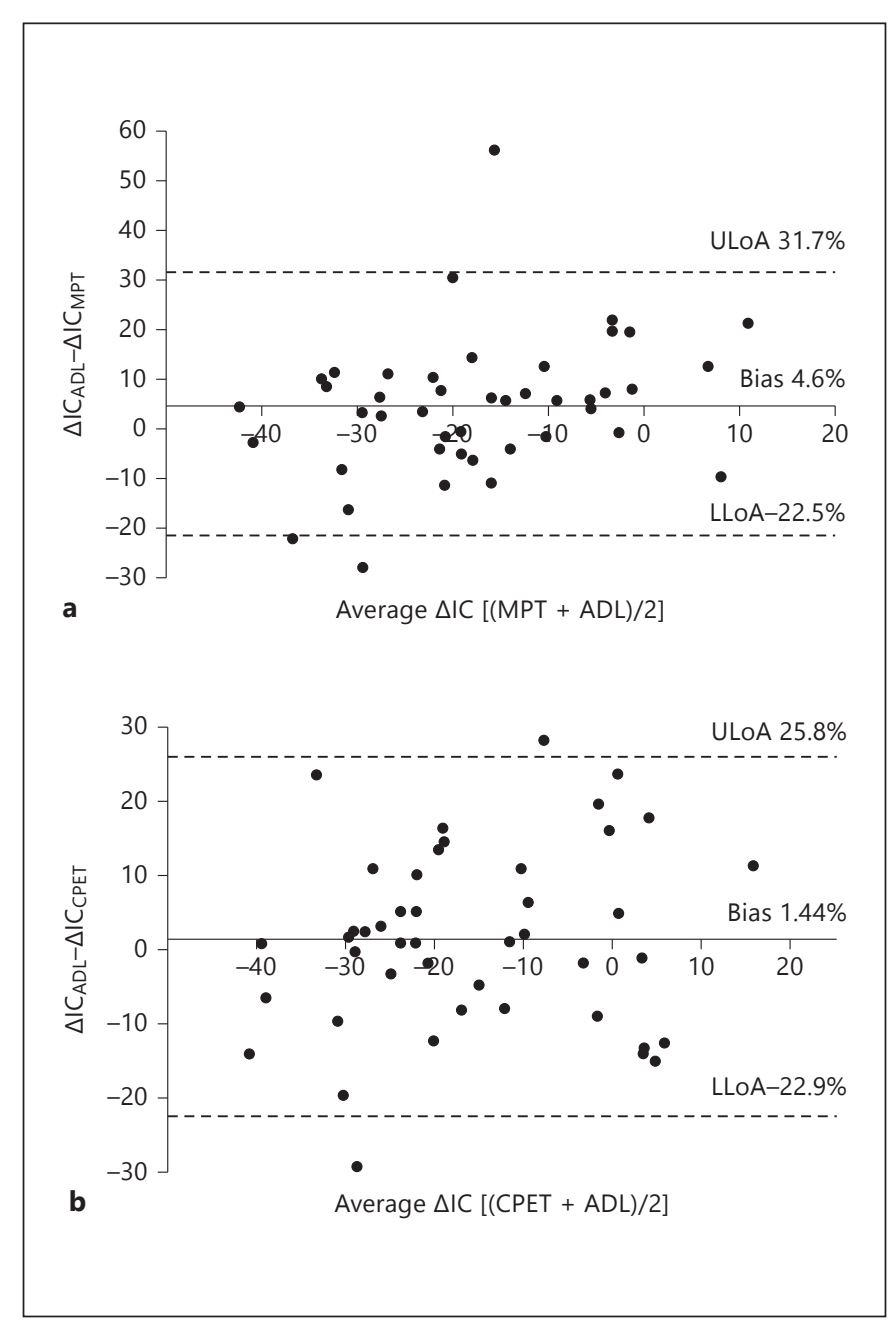

Fig. 1. Bland-Altman plots comparing the individual responses to MPT (a) and CPET (b) with ADL. The intersection of the Y and X axes represents the bias between the 2 methods. The dotted lines represent the upper and lower limits of agreement.

decrease) did show DH during CPET ( $>11.5 \%$ decrease in IC) and 1 hyperinflator during $\mathrm{ADL}\left(\triangle \mathrm{IC}_{\mathrm{ADL}}>10 \%\right.$ decrease) did not show DH during CPET. With MPT, 7 patients were incorrectly identified; 4 nonhyperinflators during ADL did show DH during MPT ( $>14.3 \%$ decrease in IC) and 3 hyperinflators during $\mathrm{ADL}\left(\Delta \mathrm{IC}_{\mathrm{ADL}}>10 \%\right.$ decrease) did not show DH during MPT.

\section{Discussion}

We addressed the issue of whether an assessment of $\mathrm{DH}$ with laboratory tests, such as CPET and MPT, can identify patients who develop DH during ADL. Our main

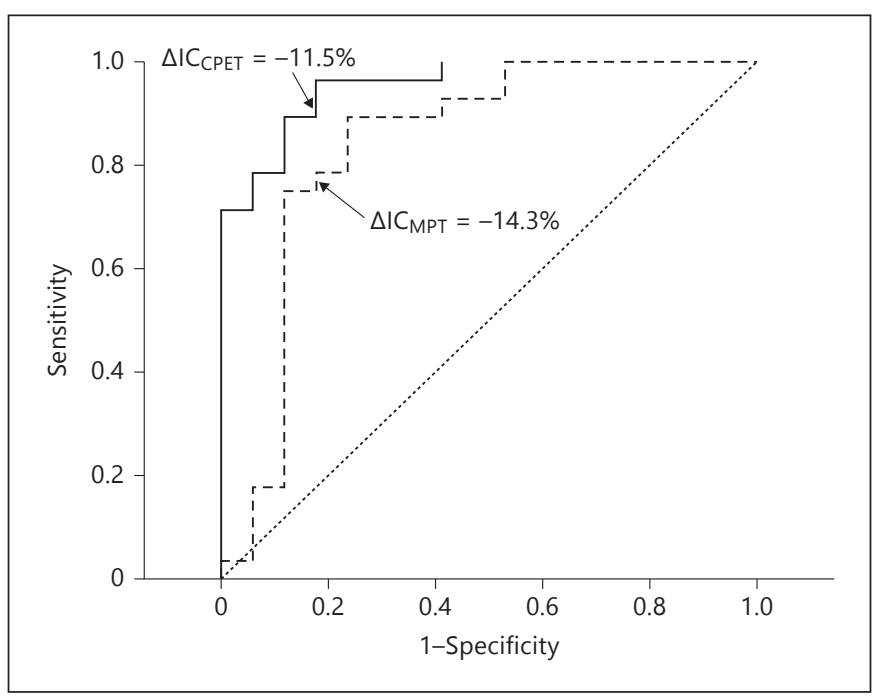

Fig. 2. ROC curve plotting the probability of a true positive (Y-axis, sensitivity) against the probability of a false positive (X-axis, 1-specificity) for all possible values of the cut-off point (reference cut-off: $\left.\Delta \mathrm{IC}_{\mathrm{ADL}}<-10 \%\right)$. For CPET, AUC $=0.956$ (95\% CI 0.903-1.009). For MPT, AUC $=0.840$ (95\% CI 0.699-0.981). Dotted line: AUC = 0.5 . Arrows indicate optimal cut-off values for $\triangle \mathrm{IC}_{\mathrm{CPET}}$ and $\triangle \mathrm{IC}_{\mathrm{MPT}}$.

Table 3. Results from ROC curve analyses with CPET and MPT used to discriminate hyperinflators and non-hyperinflators

\begin{tabular}{lllll}
\hline & AUC \pm SE & $\begin{array}{l}\text { Optimal } \\
\text { cut-off value }\end{array}$ & Sensitivity & Specificity \\
\hline CPET & $0.956 \pm 0.027^{*}$ & $-11.5 \%$ & $96 \%$ & $83 \%$ \\
MPT & $0.840 \pm 0.072^{*}$ & $-14.3 \%$ & $89 \%$ & $77 \%$ \\
\hline
\end{tabular}

$* \mathrm{p}<0.001$. Cut-off value for reference standard (ADL-induced $\Delta \mathrm{IC})$ was $-10 \%$.

finding is that both CPET and MPT have good overall accuracy to be able to discriminate between patients who develop DH during ADL and those who do not.

\section{Sensitivity and Specificity of CPET and MPT}

The overall accuracy of CPET and MPT to discriminate between hyperinflators and nonhyperinflators was demonstrated by ROC curve analyses (fig. 2). With both methods, the AUC was high. The greater accuracy of CPET in distinguishing hyperinflators from nonhyperinflators resulted in higher sensitivity and specificity than with MPT. The high sensitivity of CPET (96\%) indicates that when $\mathrm{DH}$ is assessed with CPET, the chances of missing patients who hyperinflate during ADL (i.e. a false- 
negative result) is low. With MPT, the risk of false-negative results is higher (a sensitivity of 89\%). Both CPET and MPT lack specificity, so there might be slight overdiagnosing with regard to ADL-induced $\mathrm{DH}$.

\section{Agreement between Methods Regarding DH}

$\mathrm{DH}$ develops when ventilatory demand increases and (expiratory) airflow is obstructed, so it would seem reasonable to assume that when a patient develops $\mathrm{DH}$ in one instance, it would also develop under any other circumstances where there is an increase in ventilatory demand. Studies have shown that CPET and MPT induce equal amounts of DH, which makes MPT a good substitute for CPET for study purposes [3,21]. On a group level, mean $\mathrm{DH}(\triangle \mathrm{IC})$ during ADL was not different from mean DH during CPET and MPT, thus MPT-induced DH might also serve as a substitute for studying ADLinduced DH. However, although we did not find significant differences in mean $\mathrm{DH}$, the Bland-Altman plots illustrated that the agreement between the methods is not enough to be able to conclude that the amount of $\mathrm{DH}$ measured during laboratory tests (CPET and MPT) always reflects the amount of ADL-induced $\mathrm{DH}$ in individual patients, i.e. for individual patient assessment, these methods cannot, in fact, be interchanged.

The Bland-Altman plots indicated that MPT, in particular, tends to induce more $\mathrm{DH}$ than $\mathrm{ADL}$ in some patients. Compared to CPET, MPT has also been shown to induce more DH in some patients [4]. The fact that, with MPT, a nonphysiological breathing rhythm is imposed on patients might have contributed to the larger amount of DH compared to CPET-induced and ADL-induced $\mathrm{DH}$. Due to the use of a metronome, inspiratory and expiratory times are equal, whereas during CPET and ADL patients tend to prolong expiratory time in order to allow the lung to deflate. However, when MPT is used as a screening tool, the breathing mechanism is less important. The presence of MPT-induced DH indicates that a patient is susceptible to developing $\mathrm{DH}$, whatever the circumstances.

The amount of ADL-induced DH found in our study is similar to that in earlier findings [5, 6]. Given the fact that the occurrence of DH is related to increased dyspnea, and decreased exercise capacity and level of physical activity, the fact that a large amount of $\mathrm{DH}$ does occur during regularly performed ADL is important $[8,22]$. Even one third of the patients with mild COPD in our study showed DH during ADL. In a recent study, also including patients with mild COPD, we found that a lower level of physical activity in patients with COPD is related to hy- perinflation during ADL, independently of the severity of airflow limitation [23]. Testing patient performance in ADL, however, is not practical in most clinical settings. Furthermore, many patients, especially those with mildto-moderate COPD, are seen in general practices, where CPET is also difficult to perform. Here, MPT could serve as a simple screening tool to find out whether patients with COPD complaining of dyspnea and limitations during $\mathrm{ADL}$ are likely to develop $\mathrm{DH}$.

Early detection of a patient's susceptibility to developing $\mathrm{DH}$ during $\mathrm{ADL}$ could allow early intervention to prevent or slow down further deterioration. So far, treatment options such as bronchodilation and exercise training with or without supplemental oxygen or heliox have been shown to have a positive effect on $\mathrm{DH}$ and consequently improve exercise capacity in patients $[24,25]$. The effect of such treatments on ADL-induced DH specifically, and thus on performance of ADL as well as the effects on physical activity, still need to be confirmed.

In conclusion, both CPET and MPT can serve as a screening surrogate to identify patients who are susceptible to developing DH during ADL. In practice, MPT is the most simple and inexpensive surrogate. However, one has to keep in mind that sensitivity with MPT is not optimal and that, with a negative MPT result but symptoms and limitations in ADL, referral for CPET or, when possible, ADL testing would indeed be advisable. When $\mathrm{DH}$ does not occur during CPET, it is unlikely to occur during ADL.

\section{Acknowledgements}

We thank the staff of the Pulmonary Function Department from the University Centre for Chronic Diseases for their excellent assistance.

The study was funded by the Lung Foundation Netherlands (project grant No. 3.4.08.040).

References

Puente-Maestu L, Garcia de Pedro J, Martinez-Abad Y, Ruiz de Ona JM, Llorente D, Cubillo JM: Dyspnea, ventilatory pattern, and changes in dynamic hyperinflation related to the intensity of constant work rate exercise in COPD. Chest 2005;128:651-656.

-2 O'Donnell DE, Webb KA: The major limitation to exercise performance in COPD is dynamic hyperinflation. J Appl Physiol 2008; 105:753-755.

-3 Gelb AF, Gutierrez CA, Weisman IM, Newsom R, Taylor CF, Zamel N: Simplified detection of dynamic hyperinflation. Chest 2004; 126:1855-1860. 
-4 Lahaije AJMC, Willems LM, van Hees HWH, Dekhuijzen PNR, van Helvoort HAC, Heijdra YF: Diagnostic accuracy of metronomepaced tachypnea to detect dynamic hyperinflation. Clin Physiol Funct Imaging 2013;33: 62-69.

5 Hannink JD, van Helvoort HA, Dekhuijzen PN, Heijdra YF: Dynamic hyperinflation during daily activities: does COPD global initiative for chronic obstructive lung disease stage matter? Chest 2010;137:1116-1121.

-6 Lahaije A, van Helvoort H, Dekhuijzen P, Heijdra Y: Physiologic limitations during daily life activities in COPD patients. Respir Med 2010;104:1152-1160.

7 Polkey MI, Kyroussis D, Hamnegard CH, Mills GH, Green M, Moxham J: Diaphragm strength in chronic obstructive pulmonary disease. Am J Respir Crit Care Med 1996;154: 1310-1317.

$\checkmark 8$ Garcia-Rio F, Lores V, Mediano O, Rojo B, Hernanz A, López-Collazo E, et al: Daily physical activity in patients with COPD is mainly associated with dynamic hyperinflation. Am J Respir Crit Care Med 2009;180:506-512.

-9 ATS/ACCP Statement on cardiopulmonary exercise testing. Am J Respir Crit Care Med 2003;167:211-277.

10 Miller MR, Hankinson J, Brusasco V, Burgos F, Casaburi R, Coates A, et al: Standardisation of spirometry. Eur Respir J 2005;26:319-338.

-11 Wanger J, Clausen JL, Coates A, Pedersen OF, Brusasco V, Burgos F, et al: Standardisation of the measurement of lung volumes. Eur Respir J 2005;26:511-522.
12 Stubbing DG, Pengelly LD, Morse JL, Jones NL: Pulmonary mechanics during exercise in subjects with chronic airflow obstruction. J Appl Physiol 1980;49:511-515.

13 Yan S, Kaminski D, Sliwinski P: Reliability of inspiratory capacity for estimating end-expiratory lung volume changes during exercise in patients with chronic obstructive pulmonary disease. Am J Respir Crit Care Med 1997; 156:55-59.

14 Wasserman K, Hansen J, Sue DY, Stringer WW, Whipp BJ: Normal values; in: Principles of Exercise Testing and Interpretation: Including Pathophysiology and Clinical Applications. Philadelphia, Lippincott Williams and Wilkins, 2005, pp 160-182.

15 Hannink J, Lahaije A, Verberkt C, Dekhuijzen $\mathrm{R}$, van Helvoort $\mathrm{H}$, Heijdra Y: Validity of Oxycon Mobile in measuring inspiratory capacity in healthy subjects. Clin Physiol Funct Imaging 2010;30:206-209.

16 MacIntyre N, Crapo RO, Viegi G, Johnson DC, van der Grinten CP, Brusasco V, et al: Standardisation of the single-breath determination of carbon monoxide uptake in the lung. Eur Respir J 2005;26:720-735.

17 Quanjer PH, Tammeling GJ, Cotes JE, Pedersen OF, Peslin R, Yernault JC: Lung volumes and forced ventilatory flows. Report Working Party Standardization of Lung Function Tests, European Community for Steel and Coal. Official Statement of the European Respiratory Society. Eur Respir J Suppl 1993;16:5-40.
18 Global Initiative for Chronic Obstructive Lung Disease: Global strategy for the diagnosis, management and prevention of COPD, 2011. http://www.goldcopd.org.

19 O'Donnell DE, Revill SM, Webb KA: Dynamic hyperinflation and exercise intolerance in chronic obstructive pulmonary disease. Am J Respir Crit Care Med 2001;164: 770-777.

20 O'Donnell DE, Travers J, Webb KA, He Z, Lam YM, Hamilton A, et al: Reliability of ventilatory parameters during cycle ergometry in multicentre trials in COPD. Eur Respir J 2009; 34:866-874.

21 Gelb AF, Taylor CF, McClean PA, Shinar CM, Rodrigues MT, Gutierrez CA, et al: Tiotropium and simplified detection of dynamic hyperinflation. Chest 2007;131:690-695.

-22 O’Donnell DE, Fluge T, Gerken F, Hamilton A, Webb K, Aguilaniu B, et al: Effects of tiotropium on lung hyperinflation, dyspnoea and exercise tolerance in COPD. Eur Respir J 2004;23:832-840.

-23 Lahaije AJMC, van Helvoort HAC, Dekhuijzen PNR, Heijdra YF: Resting and ADL-induced dynamic hyperinflation explain physical inactivity in COPD better than FEV1. Respir Med 2013;107:834-840.

24 Casaburi R: Strategies to reduce dynamic hyperinflation in chronic obstructive pulmonary disease. Pneumonol Alergol Pol 2009;77: 192-195.

25 Puente-Maestu L, Stringer WW: Hyperinflation and its management in COPD. Int J Chron Obstruct Pulmon Dis 2006;1:381-400. 